\title{
Squirrel monkey active conflict test
}

\author{
JEFFREY G. CANON and VINCENT P. HOUSER \\ Cardiovascular-CNS Research Section, Lederle Laboratories, Pearl River, New York 10965
}

\begin{abstract}
Ten female squirrel monkeys (Saimiri sciureus) were subjected to a discrete trial conflict procedure which contained an active avoidance contingency. Failure to respond during conflict trials was therefore punished. Several classes of clinically active anxiolytics, including the benzodiazepines (chlordiazepoxide and diazepam), carbamates (meprobamate), and barbiturates (sodium phenobarbital and sodium pentobarbital), were tested to determine if these drugs could alter behavior generated by this schedule. The potency and efficacy of the above anxiolytic drugs compared favorably with the clinical activity of these agents in man. Several other nonanxiolytic compounds (chlorpromazine, amitriptyline, and d-amphetamine) were tested to ascertain the specificity of the above procedure in detecting the anxiolytic properties of drugs. None of these latter compounds produced an anxiolytic effect in this conflict procedure. It thus appears that this particular animal model may be a useful tool in evaluating the potency and efficacy of drugs commonly used for the treatment of anxiety in man.
\end{abstract}

Behavioral pharmacologists have traditionally relied upon two basic procedures to evaluate the anxiolytic properties of psychoactive drugs. These tests include: conditioned suppression of ongoing behavior (Estes \& Skinner, 1941) and various types of conflict procedures (Masserman \& Yum, 1946; Miller \& Barry, 1960). For a variety of reasons, the latter behavioral test has gained wider support and use as a tool in evaluating anxiolytic compounds (Millenson \& Leslie, 1974). A common feature of all conflict procedures is the fact that the experimental subject is both punished and rewarded for emitting a specific behavioral response. By making the punishment contingency aversive enough, the animal can be conditioned to withhold the execution of such a response. Treatment with known anxiolytic drugs, however, releases this suppressed behavior and animals will typically emit behavioral responses that have been punished.

The conflict procedure most often employed consists of a multiple schedule (Geller, Kulak, \& Seifter, 1962; Miller \& Barry, 1960) in which rats trained on a variable interval (VI) schedule are periodically presented with a continuous reinforcement (CRF) period in which every response is both rewarded and punished. Standard anxiolytic agents such as the benzodiazepines, meprobamate, and some barbiturates typically act to disinhibit suppressed behavior, thus leading to a significant elevation in the number of punished responses that are emitted. Although most of the conflict studies in the recent drug literature

All requests for reprints should be sent to the first author at: Department of Pharmacology, Schering Corporation, B-6-2, Bloomfield, New Jersey 07003. have utilized the rat as the experimental subject, some investigators have reported favorable results with various monkey species (Cook \& Catania, 1964; Hansen, Witoslawski, \& Campbell, 1967; Miczek, 1973; Stein \& Berger, 1971).

The present paper presents a new conflict model that can be used in conjunction with various primate species. This procedure consists of a multiple schedule that presents two distinct types of discrete trials (i.e., punished and nonpunished) to the animal subjects. In addition, an active avoidance contingency is present that punishes the withholding of a response during any given conflict trial. Thus, unlike traditional conflict schedules, animals can avoid punishment only by making appropriate responses during each conflict trial. Since many psychoactive agents, including neuroleptics, are known to block avoidance responding (Cook \& Catania, 1964), the addition of this contingency to the conflict model allows one to access a variety of pharmacological activities within the framework of a single test. This fact, coupled with the evidence, summarized below, that this test can provide a sensitive and selective index of anxiolytic activity suggests that this conflict model may have utility in evaluating the CNS properties of numerous psychoactive agents.

\section{METHOD}

\section{Subjects}

Ten squirrel monkeys (Saimiri sciureus, female), weighing from 450 to $650 \mathrm{~g}$, average weight $530 \mathrm{~g}$, were used during the course of these experiments. They were given access to food ad lib except when tested. Their liquid intake was restricted to the amount obtained in the test chamber and $1 \mathrm{~h}$ of free water in the afternoon. During weekends and holidays, supplemental drinking time was allowed in order that the daily fluid intake remain constant. Each 
test animal was housed individually in a stainless steel cage of the following dimensions: $76.2 \times 54.6 \times 58.4 \mathrm{~cm}$.

\begin{abstract}
Apparatus
The operant test chambers consisted of two modified Skinner boxes (Foringer) $24.7 \times 26.7 \times 27.3 \mathrm{~cm}$. Two levers were located on one wall $14 \mathrm{~cm}$ from the grid floor and $10.2 \mathrm{~cm}$ apart. A light was positioned directly above each lever. A grid floor (12 stainless steel rods) was electrified by a fully solid-state constant wattage shock generator-scrambler unit, SGS 001 (BRS, Behavioral Research Systems). A Foringer liquid dipper was situated between the two levers and was used to deliver $0.1 \mathrm{ml}$ of liquid reward (50\% unsweetened orange juice). Houselights and a 3-in. speaker were mounted in an enclosure on the opposite wall. All programming and data collection were implemented through BRS solid-state modules and Roytron (Model 518) paper-tape punches.
\end{abstract}

\section{Procedure}

The test procedure consisted of a two-lever approach-avoidance discrete trial schedule with an active avoidance contingency superimposed on the conflict portion of the schedule. Daily sessions were $60 \mathrm{~min}$ in duration and consisted of the random presentation of reinforcement and conflict trials in a ratio of $40 \%$ reinforcement trials to $60 \%$ conflict trials. Since each trial was followed by a $30-\mathrm{sec}$ intertrial interval, the maximum number of trials per session was 120. Each session began with onset of the houselight located in the test chamber. The initiation of a reinforcement trial was signaled by the illumination of a cue light which was mounted directly above the right response lever. A correct response (i.e., depression of the right lever) was reinforced with $0.1 \mathrm{ml}$ of $50 \%$ unsweetened orange juice delivered via the liquid dipper located in the chamber. A response on the left lever simply terminated the reinforcement trial (i.e., turned off the cue light over the right lever) without producing reinforcement. If no response was made on either lever, the trial was automatically terminated after $99 \mathrm{sec}$. Each trial was separated by a 30 -sec ITI in which no cue lights were illuminated.

A conflict trial was signaled by the onset of the cue lights over both the left and right levers as well as the onset of an audible tone. A response on the right lever delivered an orange juice reward immediately via the liquid dipper, followed by an unavoidable footshock ( $0.5 \mathrm{sec}$ in duration) that was always delivered $10 \mathrm{sec}$ from the initiation of the conflict trial. A response on the left lever terminated the trial (i.e., turned off both cue lights as well as the tone), thus avoiding both the footshock and orange juice reinforcement. If no response on either lever was made within $10 \mathrm{sec}$ of the initiation of a conflict trial, the trial was automatically terminated and the animals was punished by the presentation of a $0.5 \mathrm{sec}$ unavoidable shock. Only the initial leverpress response during any given trial was effective in altering the reinforcement contingencies outlined above. Thus, secondary responses on either lever during the ITI had no consequences upon shock or reinforcement delivery. Suppression of right lever responding during conflict trials was contingent upon shock intensity and was thus varied from animal to animal to produce equivalent levels of response inhibition (i.e., .05 to $.5 \mathrm{~W}$ or approximately 1.5 to $4.0 \mathrm{~mA}$ ).

A fully trained squirrel monkey would normally make practically all its responses on the right lever during reinforcement trials, and all its responses on the left lever during conflict trials. This response pattern thus maximized the number of liquid rewards delivered, while minimizing the number of shocks obtained. Few response failures during either type of trial were recorded during control performance. Monkeys were tested daily, 5 days a week, to maintain maximum behavioral stability for drug testing.

\section{Drugs}

All compounds were prepared in $2 \%$ starch suspension and administered orally $1 \mathrm{~h}$ prior to the experimental session. The starch vehicle was always given the day before drug dosing. The dosing volume was $1.0 \mathrm{ml} / \mathrm{kg}$. The doses of some compounds were titrated to individual monkeys in order to obtain a dose response function as well as the minimum effective dose required to elevate punished responding. The following list summarizes the drugs and dosages utilized in the present study: chlorpromazine hydrochloride $(1.0,2.0,4.0 \mathrm{mg} / \mathrm{kg})$, chlordiazepoxide hydrochloride $(5.0,7.5,10.0,15.0 \mathrm{mg} / \mathrm{kg})$, diazepam $(0.5,1.0,2.0 \mathrm{mg} /$ $\mathrm{kg})$, meprobamate $(100,125,150 \mathrm{mg} / \mathrm{kg})$, sodium phenobarbital $(5.0,10.0,20.0,40.0 \mathrm{mg} / \mathrm{kg})$, sodium pentobarbital $(5.0,7.5$, $10.0,12.5 \mathrm{mg} / \mathrm{kg})$, amitriptyline hydrochloride $(2.5,5.0,10.0 \mathrm{mg}$ / $\mathrm{kg})$, and d-amphetamine sulfate $(0.25,0.50,1.0 \mathrm{mg} / \mathrm{kg})$.

\section{RESULTS}

The length of time required to train squirrel monkeys in the two-lever procedure varied from 3 to 6 months when autoshaping methods were utilized. If hand-shaping techniques were employed, this time period could be greatly reduced. Even under the most optimum conditions, however, a certain percentage of animals (i.e., 10\%-25\%) would fail to acquire the desired behavior and thus were discarded from the experimental group. The remaining animals when fully trained consistently demonstrated the following pattern of behavior. During reinforcement trials, the animals would always depress the right lever to attain a reward, while conflict trials generally elicited an avoidance (i.e., left-lever) response. Each discrete trial was followed by some type of response, with few response omissions or errors being recorded under control conditions. The above behavior pattern was quite stable, and thus control performance was maintained over the entire experimental period even though many types of drugs were administered to the animals.

The two major motivational variables that contributed to stable performance included the level of water deprivation and the shock intensity. The level of deprivation was reflected by the percentage of reinforcement trials that elicited a response on the right lever, while the shock intensity influenced the number of punished responses that would be emitted during conflict trials under control conditions. The data contained in Tables 1 and 2 demonstrate how

Table 1

Level of Liquid Deprivation vs. Percent of Trials Reinforced During Reinforcement Trials

\begin{tabular}{|c|c|c|c|c|}
\hline \multirow[b]{2}{*}{ Monkey } & \multicolumn{2}{|c|}{ 1/2-h Drinking Period } & \multicolumn{2}{|c|}{ 1-h Drinking Period } \\
\hline & Water* & Trials** & Water* & Trials** \\
\hline 23 & 60 & 100 & 80 & 100 \\
\hline 41 & 40 & 100 & 90 & $5 \dagger$ \\
\hline 67 & 40 & 98 & 80 & 100 \\
\hline 43 & 20 & 100 & 70 & 100 \\
\hline 2 & 60 & 88 & 100 & $58 \dagger$ \\
\hline
\end{tabular}

Note-Deprivation is controlled by $1 / 2-h$ and $1-h$ supplemental drinking period on the day before the test session.

*Water (in milliliters) consumed during supplemental period. **Percent of trials reinforced.

tMonkeys 41 and 2 response rate recovered the following day when the drinking period was reduced to $1 / 2 h$. 
Table 2

Percent Responses Punished vs. Shock Intensity (mA) for Monkeys 67 and 43

\begin{tabular}{cccc}
\hline & \multicolumn{3}{c}{ Percent Responses Punished } \\
\cline { 2 - 4 } Monkey & \multicolumn{3}{c}{ Shock Intensity } \\
\hline 67 & 2.0 & 3.0 & 4.0 \\
43 & 33 & 14 & \\
\hline
\end{tabular}

manipulations of these two variables affected behavior under the control of this schedule of reinforcement. Table 1 indicates that as the deprivation level was decreased (i.e., supplemental drinking time increased from $1 / 2 \mathrm{~h}$ to $1 \mathrm{~h}$, the percentage of reinforcement trials that produced a right leverpress response followed by a liquid reward was reduced in two of the five animals tested. Thus, deprivation level directly affects the performance of animals, particularly during the reinforcement trials of this multiple schedule. Table 2 presents data for two animals who were subjected to various shock intensities during the conflict portion of this schedule. As the data in Table 2 indicate, shock intensity is inversely related to the level of punished responding emitted by the animal. As the shock level is increased, the percentage of conflict trials that produce a right leverpress (i.e., punished responses) are decreased. As training continued, the two animals referred to in Table 2 (i.e., monkeys 67 and 43) reduced their level of punished responding to 0 in response to the 3.0and 4.0-mA shock levels. By titrating shock levels for each animal, a zero level of punished responding could be maintained over long periods of time.

Table 3 summarizes the effects of the various CNS active drugs upon reinforcement responding during reinforcement trials, as well as punished responding and response failures (i.e., block of avoidance) during conflict trials. The varying number of animals in each dose group merely reflects the fact that individual animals demonstrated different sensitivities to these particular drugs. Thus, animals that demonstrated acute sensitivity to low doses of a specific drug were not treated with higher doses, while insensitive animals did not receive the full range of lower doses.

Table 3

The Effect of Various Drugs on Three Classes of Responding in the Squirrel Monkey Active Conflict Test

\begin{tabular}{|c|c|c|c|c|c|c|c|c|c|c|c|}
\hline & \multirow{2}{*}{$\begin{array}{c}\text { Dose } \\
(\mathrm{mg} / \mathrm{kg})\end{array}$} & \multirow[b]{2}{*}{$\mathrm{N}$} & \multicolumn{3}{|c|}{ Reinforced Responses } & \multicolumn{3}{|c|}{ Punished Responses } & \multicolumn{3}{|c|}{$\begin{array}{c}\text { Response Failures } \\
\text { During Conflict }\end{array}$} \\
\hline & & & $\mathrm{C}$ & $\mathrm{D}$ & $\Delta \pm \mathrm{SE}$ & $\mathrm{C}$ & $\mathrm{D}$ & $\Delta \pm \mathrm{SE}$ & $\mathrm{C}$ & D & $\Delta \pm \mathrm{SE}$ \\
\hline Chlordiazepoxide & $\begin{array}{r}2.5 \\
5.0 \\
7.5 \\
10.0 \\
15.0\end{array}$ & $\begin{array}{l}2 \\
5 \\
6 \\
4 \\
2\end{array}$ & $\begin{array}{l}21 \\
36 \\
39 \\
45 \\
47\end{array}$ & $\begin{array}{l}42 \\
44 \\
43 \\
33 \\
45\end{array}$ & $\begin{array}{l}+21 \pm 2 * \\
+8 \pm 7 \\
+4 \pm 4 \\
-12 \pm 13 \\
-2 \pm 1\end{array}$ & $\begin{array}{l}5 \\
3 \\
4 \\
4 \\
4\end{array}$ & $\begin{array}{l}13 \\
15 \\
17 \\
15 \\
18\end{array}$ & $\begin{array}{l}+8 \pm 3 \\
+12 \pm 4^{*} \\
+13 \pm 5^{*} \\
+11 \pm 6 \\
+14 \pm 6\end{array}$ & $\begin{array}{l}1 \\
0 \\
0 \\
3 \\
1\end{array}$ & $\begin{array}{l}1 \\
1 \\
2 \\
7 \\
0\end{array}$ & $\begin{array}{r}0 \pm 1 \\
+1 \pm 1 \\
+2 \pm 1 \\
+4 \pm 6 \\
-1 \pm 1\end{array}$ \\
\hline Diazepam & $\begin{array}{r}.5 \\
1.0 \\
2.0\end{array}$ & $\begin{array}{l}4 \\
6 \\
8\end{array}$ & $\begin{array}{l}46 \\
45 \\
44\end{array}$ & $\begin{array}{l}45 \\
46 \\
38\end{array}$ & $\begin{array}{l}+1 \pm 2 \\
+1 \pm 2 \\
-6 \pm 6\end{array}$ & $\begin{array}{l}7 \\
2 \\
3\end{array}$ & $\begin{array}{l}16 \\
12 \\
15\end{array}$ & $\begin{array}{l}+9 \pm 5 \\
+10 \pm 4^{*} \\
+12 \pm 5^{*}\end{array}$ & $\begin{array}{l}1 \\
0 \\
0\end{array}$ & $\begin{array}{l}1 \\
2 \\
1\end{array}$ & $\begin{array}{r}0 \pm 1 \\
+2 \pm 1 \\
+1 \pm 1\end{array}$ \\
\hline Chlorpromazine & $\begin{array}{l}1.0 \\
2.0 \\
4.0\end{array}$ & $\begin{array}{l}7 \\
7 \\
6\end{array}$ & $\begin{array}{l}35 \\
33 \\
39\end{array}$ & $\begin{array}{l}34 \\
31 \\
23\end{array}$ & $\begin{array}{l}-1 \pm 2 \\
-2 \pm 6 \\
-16 \pm 5^{* *}\end{array}$ & $\begin{array}{l}5 \\
3 \\
3\end{array}$ & $\begin{array}{r}4 \\
2 \\
10\end{array}$ & $\begin{array}{l}+1 \pm 1 \\
-1 \pm 2 \\
+7 \pm 3 *\end{array}$ & $\begin{array}{l}1 \\
0 \\
2\end{array}$ & $\begin{array}{l}0 \\
1 \\
5\end{array}$ & $\begin{array}{l}-1 \pm 1 \\
+1 \pm 1 \\
+3 \pm 1\end{array}$ \\
\hline d-Amphetamine & $\begin{array}{r}.25 \\
.50 \\
1.00\end{array}$ & $\begin{array}{l}3 \\
4 \\
3\end{array}$ & $\begin{array}{l}30 \\
48 \\
45\end{array}$ & $\begin{array}{r}2 \\
1 \\
10\end{array}$ & $\begin{array}{l}-28 \pm 11 \\
-47 \pm 2 * * \\
-45 \pm 4 * *\end{array}$ & $\begin{array}{l}1 \\
3 \\
2\end{array}$ & $\begin{array}{l}1 \\
0 \\
1\end{array}$ & $\begin{array}{r}0 \pm 1 \\
+3 \pm 2 \\
-1 \pm 1\end{array}$ & $\begin{array}{l}0 \\
0 \\
0\end{array}$ & $\begin{array}{l}1 \\
4\end{array}$ & $\begin{array}{c}0 \pm \\
+1 \pm 1 \\
+4 \pm 4\end{array}$ \\
\hline Meprobamate & $\begin{array}{l}100 \\
125 \\
150\end{array}$ & $\begin{array}{l}3 \\
8 \\
3\end{array}$ & $\begin{array}{l}40 \\
34 \\
24\end{array}$ & $\begin{array}{l}41 \\
36 \\
27\end{array}$ & $\begin{array}{r}+1 \pm 4.6 \\
+1 \pm 4.3 \\
+3 \pm 10.3\end{array}$ & $\begin{array}{l}1 \\
2 \\
2\end{array}$ & $\begin{array}{l}13 \\
10 \\
12\end{array}$ & $\begin{array}{l}+12 \pm 8.5 \\
+8 \pm 2.4^{*} \\
+10 \pm 1.2^{*}\end{array}$ & $\begin{array}{l}0 \\
0 \\
0\end{array}$ & $\begin{array}{l}0 \\
2 \\
3\end{array}$ & $\begin{aligned} & 0 \pm \\
+2 & \pm .56 \\
+3 & \pm 2.6\end{aligned}$ \\
\hline Sodium Phenobarbital & $\begin{array}{r}5.0 \\
10.0 \\
20.0 \\
40.0\end{array}$ & $\begin{array}{l}3 \\
7 \\
7 \\
3\end{array}$ & $\begin{array}{l}41 \\
43 \\
45 \\
40\end{array}$ & $\begin{array}{l}47 \\
43 \\
44 \\
29\end{array}$ & $\begin{array}{rr}+6 \pm & 7.5 \\
0 \pm & 2.8 \\
-1 \pm 2.4 \\
-11 \pm 12.1\end{array}$ & $\begin{array}{l}0 \\
1 \\
2 \\
7\end{array}$ & $\begin{array}{r}1 \\
4 \\
10 \\
11\end{array}$ & $\begin{array}{l}+1 \pm .9 \\
+3 \pm 2.1 \\
+8 \pm 4.7 * \\
+4 \pm 8.5\end{array}$ & $\begin{array}{l}0 \\
0 \\
0 \\
0\end{array}$ & $\begin{array}{l}0 \\
1 \\
1 \\
8\end{array}$ & $\begin{array}{l}0 \pm \\
1 \pm .3 \\
1 \pm .6 \\
8 \pm 6.8\end{array}$ \\
\hline Sodium Pentobarbital & $\begin{array}{r}5.0 \\
7.5 \\
10.0 \\
12.5\end{array}$ & $\begin{array}{l}9 \\
4 \\
9 \\
4\end{array}$ & $\begin{array}{l}42 \\
42 \\
43 \\
41\end{array}$ & $\begin{array}{l}41 \\
45 \\
43 \\
43\end{array}$ & $\begin{array}{r}-2 \pm 2.0 \\
+2 \pm 1.0 \\
0 \pm 2.1 \\
+2 \pm 8.3\end{array}$ & $\begin{array}{l}2 \\
2 \\
2 \\
0\end{array}$ & $\begin{array}{l}2 \\
8 \\
8 \\
8\end{array}$ & $\begin{aligned} 0 \pm .6 \\
+7 \pm 3.8 \\
+7 \pm 3.2 * \\
+8 \pm 5.1\end{aligned}$ & $\begin{array}{l}0 \\
0 \\
0 \\
0\end{array}$ & $\begin{array}{l}0 \\
3 \\
1 \\
4\end{array}$ & $\begin{array}{l}0 \pm \\
2 \pm 1.8 \\
1 \pm .4 \\
4 \pm 2.0\end{array}$ \\
\hline Amitryptyline & $\begin{array}{r}2.5 \\
5.0 \\
10.0\end{array}$ & $\begin{array}{l}3 \\
5 \\
5\end{array}$ & $\begin{array}{l}23 \\
36 \\
38\end{array}$ & $\begin{array}{l}33 \\
32 \\
31\end{array}$ & $\begin{array}{l}+10 \pm 15.0 \\
-4 \pm 6.0 \\
-7 \pm 11.1\end{array}$ & $\begin{array}{l}3 \\
3 \\
3\end{array}$ & $\begin{array}{l}2 \\
0 \\
2\end{array}$ & $\begin{array}{l}-1 \pm 1.0 \\
-3 \pm 1.7 \\
-1 \pm 1.0\end{array}$ & $\begin{array}{l}0 \\
0 \\
0\end{array}$ & $\begin{array}{l}0 \\
0 \\
9\end{array}$ & $\begin{array}{l}0 \pm \\
0 \pm \\
9 \pm 5.7\end{array}$ \\
\hline
\end{tabular}

Note-Statistical comparisons are made between control (C) and drug (D) measures using a paired (one-tailed) $t$ test.

${ }^{*} p \leqslant .05$

$* * p \leqslant .01$ 


\section{Chlordiazepoxide}

As the data in Table 3 indicate, chlordiazepoxide in doses of 5.0 and $7.5 \mathrm{mg} / \mathrm{kg} \mathrm{P.O}$. produced significant $(p<.05)$ mean increases in punished responding during conflict trials. Individual monkey data is presented in Figures 1 and 2, which indicate that this effect was dose related. Each monkey, however, demonstrated differential sensitivity to the various doses tested, thus enhancing the variability of the grouped data. During reinforcement trials, chlordiazepoxide administration either increased respond- ing in those animals with low baseline rates (i.e., monkey 955) or had no effect. The monkeys exhibited increased levels of motor activity and locomotion in the test chamber under drug conditions, but generally showed reduced activity along with noticeable hind-leg ataxia in the home cage. The higher dosages $(10.0,15.0 \mathrm{mg} / \mathrm{kg})$ produced elevations in punished responding, but due to the number of animals and variability (monkey 1 incapacitated at $10.0 \mathrm{mg} / \mathrm{kg}$ ) these changes were not statistically significant $(\mathrm{p}>.05)$.

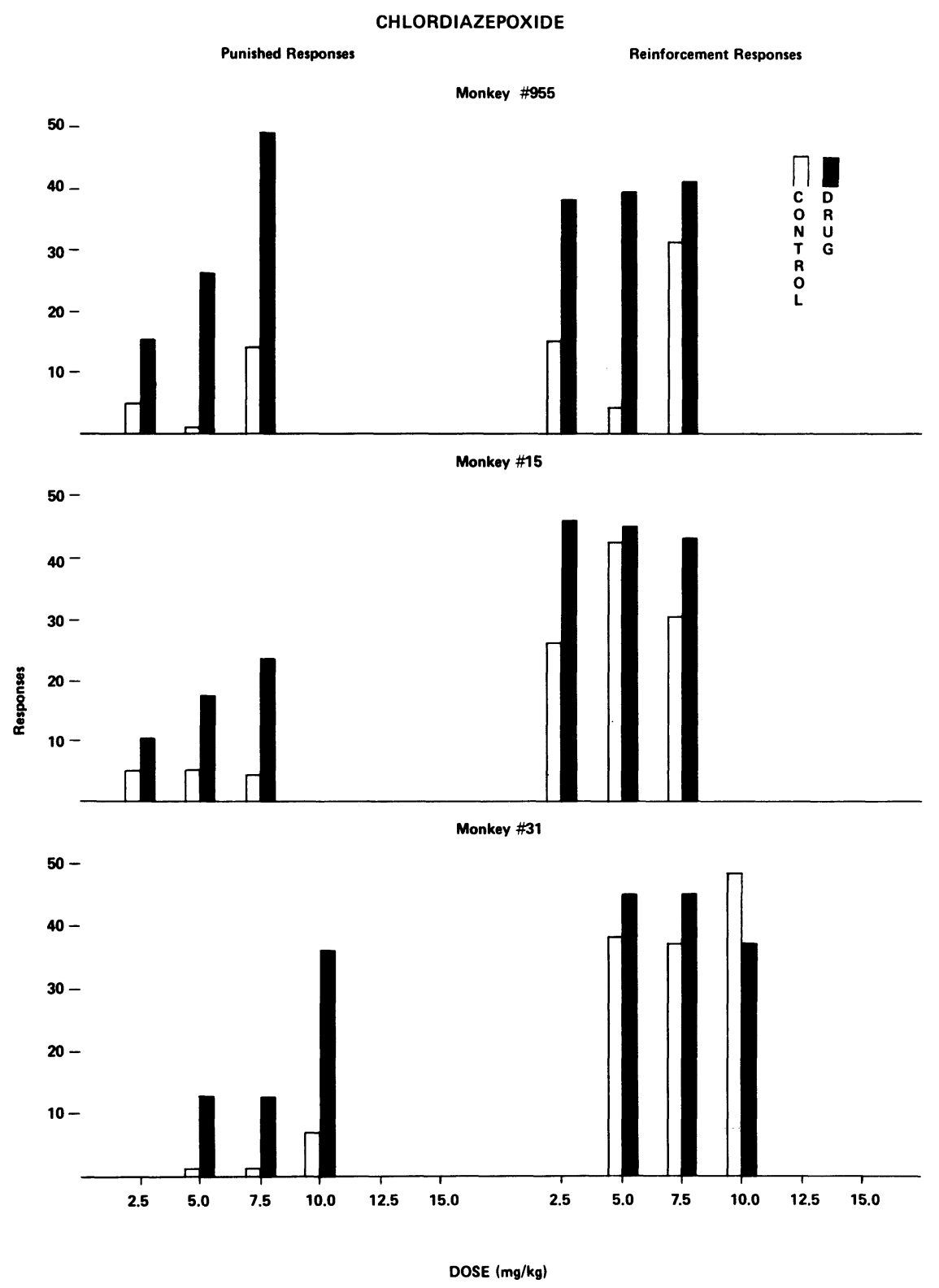

Figure 1. Punished and reinforced responses for individual monkeys subjected to various doses of chlordiazepoxide. The control bar (open) represents data obtained when the monkey was dosed with vehicle, P.O., $1 \mathrm{~h}$ prior to behavioral testing on the day before drug administration. Similarly, the solid bar represents the data when chlordiazepoxide was administered. 
CHLORDIAZEPOXIDE

Punished Responses

Reinforcement Responses
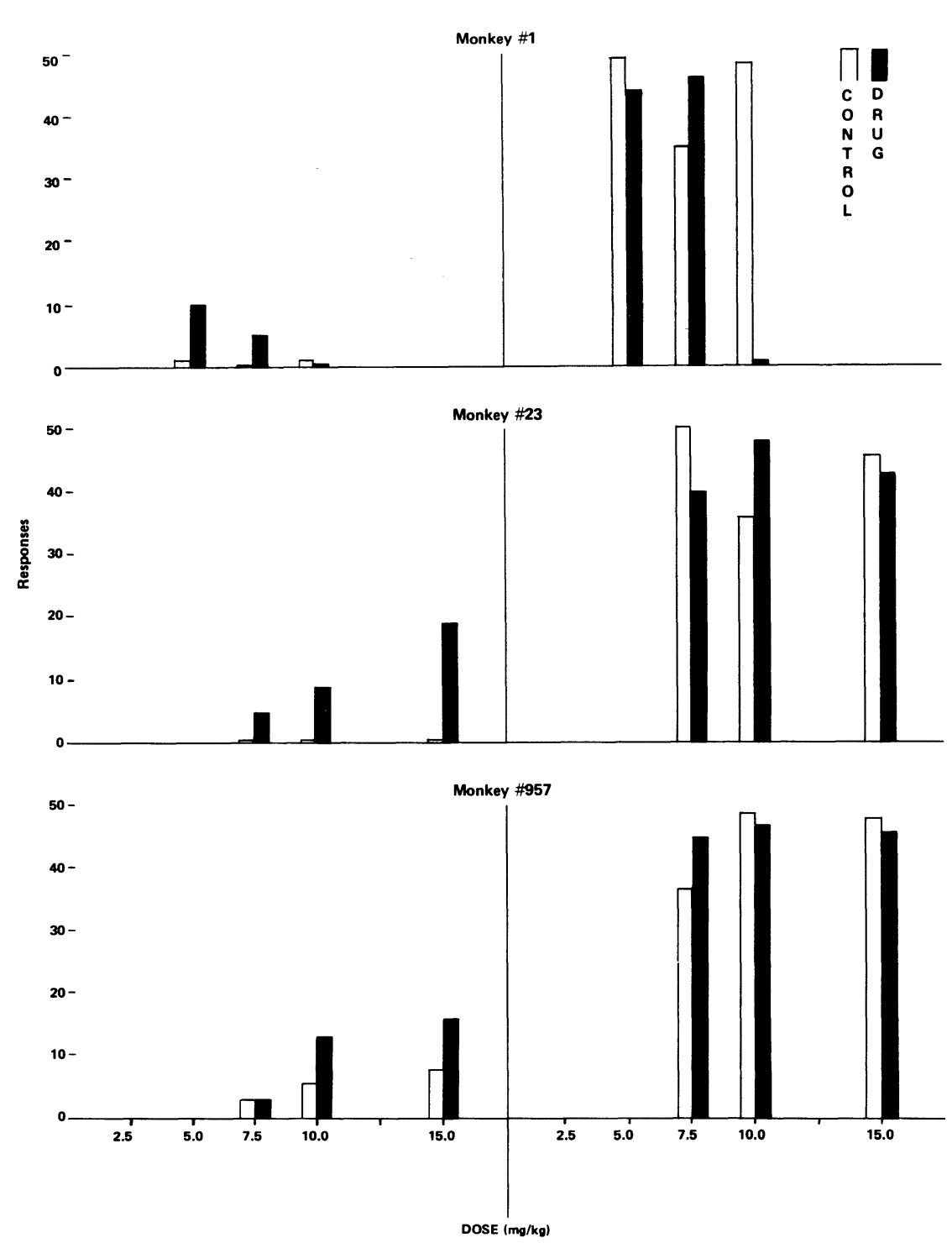

Figure 2. Punished and reinforced responses for individual monkeys subjected to various doses of chlordiazepoxide. The control bar (open) represents data obtained when the monkey was dosed with vehicle, P.O., $1 \mathrm{~h}$ prior to behavioral testing on the day before drug administration. Similarly, the solid bar represents the data when chlordiazepoxide was administered.

\section{Diazepam}

Diazepam, like chlordiazepoxide, increased punished responding without significantly decreasing the number of reinforced responses elicited. Table 3 indicates that significant increases in punished responding were recorded at both the 1.0- and 2.0$\mathrm{mg} / \mathrm{kg}$ dose levels. With the exception of a slight drop in the reinforced responses at $2.0 \mathrm{mg} / \mathrm{kg}$, the results were very similar to that noted after chlordiazepoxide administration. Overtly, the monkeys exhibited mild hind-leg ataxia at the higher doses but this did not appear to affect leverpressing.

\section{Meprobamate}

Another clinical agent used in the treatment of anxiety, meprobamate, also showed a positive effect by increasing the number of punished responses emitted without significantly altering the number of reinforced responses recorded at doses of 125 and $150 \mathrm{mg} / \mathrm{kg}$, P.O. (Table 3). As was the case with the benzodiazepines, meprobamate at the two highest doses produced a depression in motor activity and a noticeable amount of hind-leg ataxia. This ataxia, however, did not appear to impede the act of leverpressing. 


\section{Chlorpromazine (CPZ)}

At 1.0 and $2.0 \mathrm{mg} / \mathrm{kg}$, P.O. CPZ did not affect either conflict or nonconflict responding (Table 3 ). However, at $4.0 \mathrm{mg} / \mathrm{kg}$ three measures were significantly $(\mathrm{p}<.05)$ affected (one-tailed Student's t test). Of the six monkeys tested, three demonstrated an increase in punished responding, five exhibited a drop in reinforcement responses during reinforcement trials, and four showed an increase in the number of response failures (i.e., block of avoidance) during conflict trials. Overt observation of these animals indicated that the drug produced increased levels of sedation and sleepiness coupled with reduced locomotion and motor activity at the $4.0 \mathrm{mg} / \mathrm{kg}$ dose.

\section{d-Amphetamine}

The CNS stimulant, d-amphetamine, at all doses, P.O., tested had no effect on punished responding (Table 3). One monkey at $1.0 \mathrm{mg} / \mathrm{kg}$ showed an intensified reaction to the conflict and continually held the avoidance lever down, thus producing 12 unavoided shocks. The most marked effect was a decrease in reinforced responding at all doses tested. This effect could be related to the anorexigenic properties of d-amphetamine. The administration of 0.5 and $1.0 \mathrm{mg} / \mathrm{kg}$ of d-amphetamine produced noticeable changes in overt behavior. The drug appeared to increase movements such as head turning and biting, which occurred repetitively as in stereotyped behavior.

\section{Phenobarbital and Pentobarbital}

The two barbiturates tested in this schedule, sodium pentobarbital and sodium phenobarbital, appeared to have similar effects across animals in that these drugs produced consistent mean increases in punished responding (Table 3). Although the effect was very clear in some monkeys, others showed little or no effect. After phenobarbital, three monkeys out of seven, as opposed to five out of nine tested with pentobarbital, showed marked increments in punished responding. The doses at which these effects occurred varied across animals. In addition, these drugs produced few changes in reinforcement responding and did not appear to block avoidance behavior during conflict trials. Monkeys that demonstrated low control response rates during reinforcement trials increased their rates after drug administration. This type of effect was mentioned earlier in regard to the chlordiazepoxide and diazepam drug treatments.

\section{Amitriptyline}

The clinical antidepressant drug, amitriptyline, was also tested in this paradigm and showed no effect on punished responding (Table 3). At the highest dose, however, two out of five monkeys tested exhibited marked depression of motor activity. Thus, responding during both reinforcement and conflict trials was greatly reduced.

In an attempt to better characterize the efficacies of those drugs which are used clinically in the treatment of anxiety, the maximum effect recorded for each monkey tested was selected (i.e., maximum number of punished responses emitted during conflict trials under drug conditions). A mean maximal effect was then computed from these data. Since individual animals differed in their sensitivity to these drugs, this computation made it possible to compare the relative efficacies of these anxiolytic drugs. Pooling the results by dose as noted by the data in Table 3 only served to cloud the magnitude of the drug's effect.

Figure 3 presents a summary of the efficacy data. This figure indicates that chlordiazepoxide and diazepam are similar in their activity and are about twice as effective as sodium phenobarbital, sodium pentobarbital, and meprobamate in increasing punished responding. Under all the drug conditions noted in Figure 3, reinforcement responding during the reinforcement trials showed no significant $(p>.05)$ change from control rates.

\section{DISCUSSION}

The present data demonstrate that monkeys trained in a two-lever conflict schedule demonstrated good behavioral stability over long periods of time, generally emitting fewer than five punished responses per session. Reinforcement responding was generally more variable initially, but as conditioning continued this behavior also stabilized. Once a monkey attained behavioral stability, it would typically respond on $100 \%$ of the trials, receiving a minimum number of shocks and obtaining the maximum number of unpunished reinforcements. In addition, this degree of stability could be maintained over an indefinite period of time. Some monkeys have been utilized in this test procedure in our laboratory for over 4 years. This feature thus makes this test procedure extremely valuable for those wishing to evaluate large numbers of compounds in an efficient manner.

In addition to the degree of behavioral stability generated, this test procedure may have several other distinct advantages over previous methods used to detect anxiolytic activity. The present procedure does not generate either fatigue or satiety in animal subjects as do other free-running operant schedules of reinforcement (i.e., VI or FR). An animal subjected to a typical FR or VI schedule may emit hundreds or even thousands of responses during a 1-h test period. The present procedure exposes the animal to a maximum of 120 discrete trials that require only one response. Thus, fatigue is probably not a factor in this particular test. In addition, under this procedure animals normally obtain a maximum of 50 individual reinforcements $(5 \mathrm{cc})$ per test session. 

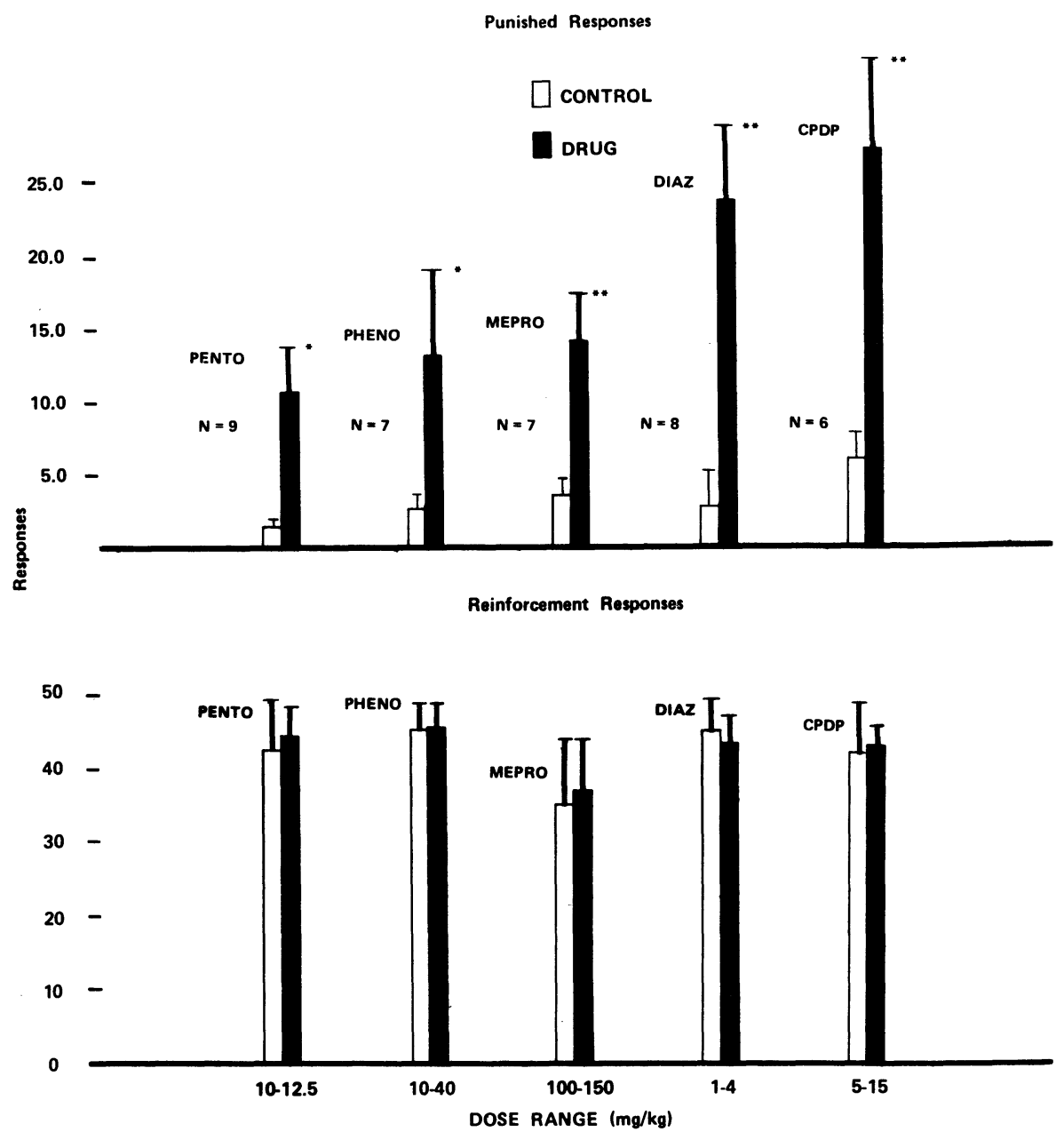

Figure 3. Mean maximum effect on punished responses under various doses of sodium pentobarbital (PENTO), sodium phenobarbital (PHENO), meprobamate (MEPRO), diazepam (DIAZ), and chlordiazepoxide (CPDP). The open bar represents the mean effect after vehicle administration, while the solid bar shows the mean maximum effect following drug administration. Route of both vehicle and drug was P.O., $1 \mathrm{~h}$ before the animal was placed in test chamber. Probability levels refer to comparisons made between control and drug sessions using a one-tailed paired $t$ test $\left({ }^{*} p<.05,{ }^{* *} p<.01\right)$.

When given ad-lib access to water, these same animals will consume $71 \mathrm{cc}$ (mean) in a 1-h period. Thus, satiation would not appear to be possible during a 1-h test session in which animals were subjected to this discrete trial procedure.

Another built-in feature of this test is the demand placed on the monkey to respond to both reinforcement and conflict situations. Most other procedures (Cook \& Catania, 1964; Geller \& Seifter, 1960; Miczek, 1973) are passive in nature during the conflict portion of the schedule (i.e., the animal receives shock only if it makes a barpress). In the present procedure, unavoidable shock is programmed to occur $10 \mathrm{sec}$ after the initiation of a conflict trial. In that interval, the monkey is thus motivated to execute one of two possible behavioral responses. Failure to respond is therefore punished. Under these contingencies, the monkey learns not only to sup- press reinforcement responding during conflict, but also to actively avoid shock by making a left leverpress response. This active avoidance component is unique to the present conflict procedure and, as such, may provide more information concerning the complex behavioral effects of CNS active drugs.

The drug results summarized in this report are in agreement with earlier data (Cook \& Davidson, 1973; Geller, Kulak, \& Seifter, 1962; Geller \& Seifter, 1960; Hansen, Witoslawski, \& Campbell, 1967; Hill, 1974) obtained using more traditional conflict procedures. Those drugs which are primarily anxiolytic in man produce consistent increases in the number of punished responses the animal emits, while not affecting its nonpunished response rate.

The most efficacious class of drugs affecting the central nervous system used in the treatment of anxiety are the benzodiazepines, of which chlordiaze- 
poxide and diazepam are the most widely prescribed (Greenblatt \& Shader, 1974). In the present paper, these drugs were, in fact, most efficacious in increasing the number of punished responses (Figure 2) emitted by squirrel monkeys. Other types of anxiolytics, such as the barbiturates and meprobamate, also produced consistent increments in punished responding, but not to the extent of the benzodiazepines. The mechanism of action of this class of drugs has been thoroughly investigated (Cook \& Davidson, 1973; Houser, 1977). It would appear that the anxiolytics do not elevate punished responding through analgesia, enhanced appetitive motivation, or loss of stimulus control, but rather by disinhibiting a central inhibitory neuronal mechanism that mediates the effects of punishment (Margules \& Stein, 1967).

To demonstrate the specificity of the monkey conflict test for anxiolytics, a representative neuroleptic (CPZ), antidepressant (amitriptyline), and a stimulant (d-amphetamine) were also evaluated. As the data indicate in Table 3, none of these drugs elevated punished responding at the doses that failed to affect the control rate of reinforcement behavior. These data are in agreement with the work of others (Cook \& Davidson, 1973; Geller et al., 1962; Hansen et al., 1967).

In order to reveal a clear dose-response relationship with regard to those drugs which increased punished resonding, it was necessary to examine individual monkey data. Thus, dose-response profiles are evident in the individual data of Figures 1 and 2, but are less evident in the pooled data of Table 3 for chlordiazepoxide. This apparent inconsistency could stem from several variables, including heterogenicity of the sample, different shock intensities, hormonal changes of the monkey, etc. In any event, by determining the maximum effect recorded for each animal under all the drugs tested, the relative efficacies of these compounds could be ascertained. As the data in Figure 3 demonstrate, the relative efficacies of the drugs tested compare favorably with clinical findings in man (Greenblatt \& Shader, 1974).

In conclusion, the present data appear to validate the present procedure as a meaningful tool for use in evaluating potential anxiolytic agents. This procedure generates stable behavioral baselines which appear to be sensitive to the anxiolytic properties of a variety of compounds which have clinical utility in man. In addition, this procedure was able to roughly estimate the efficacy of the various compounds tested. Finally, use of this technique over an extended period has demonstrated the utility of this procedure in research programs that require longterm chronic testing.

\section{REFERENCES}

Cook, L., \& Catania, C. Effect of drugs on avoidance and escape behavior. Federation Proceedings, 1964, 23, 818-835.

Cook, L., \& Davidson, A. B. Effects of behaviorally active drugs in a conflict-punishment procedure in rats. In $S$. Garattine, E. Mussini, \& L. Randall (Eds.), The benzodiazepines. New York: Raven Press, 1973.

Estes, W. K., \& SkinneR, B. F. Some quantitative properties of anxiety. Journal of the Experimental Analysis of Behavior, 1941, 29, 390-400.

Geller, I., Kulak, J. T., \& Seifter, J. The effects of chlordiazepoxide and chlorpromazine on a punishment discrimination. Psychopharmacologia, 1962, 3, 374-385.

Geller, I., \& Seifter, J. The effects of meprobamate, barbiturates, d-amphetamine and promazine on experimentally induced conflict in the rat. Psychopharmacologia, 1960, 1, $482-492$.

Greenblatt, D. J., \& Shader, R. I. Benzodiazepines in clinical practice. New York: Raven Press, 1974.

Hansen, H. M. Witoslawski, J. J., \& Campbell, E. H. Drug effects in squirrel monkeys trained on a multiple schedule with a punishment contingency. Journal of the Experimental Analysis of Behavior, 1967, 10, 565-569.

Hisl, R. T. Fixed ration conflict: A sensitive procedure for detection and evaluation of anxiolytic drug activity in rats. Journal de pharmacologie, 1974, 5, 43.

Houser, V. P. The effects of drugs upon behavior controlled by aversive stimuli. In D. E. Blackman \& D. J. Sanger (Eds.), Contemporary research in behavioral pharmacology. New York: Plenum, 1977. Pp. 69-157.

Margules, D. L., \& Stein, L. Neuroleptics vs. tranquilizers: Evidence from animal behavior studies of mode and site of action. In H. Brill, J. D. Cole, P. Deniker, H. Hippins, \& P. O. Bradley (Eds.), Neuropsychopharmacology. Amsterdam: Excerpta Medica, 1967. Pp. 108-120.

Masserman, J. H., \& Yum, K. S. An analysis of the influence of alcohol on experimental neurosis in cats. Psychosomatic Medicine, 1946, 8, 36-52.

MiczeK, K. A. Effects of scopolamine, amphetamine and chlordiazepoxide on punishment. Psychopharmacologia, 1973, 28, 373-389.

Millenson, J. R., \& Leslie, T. The conditioned emotional response (CER) as a baseline for the study of antianxiety drugs. Neuropharmacology, 1974, 13, 1-9.

Miller, N. E., \& BARRY III, H. Motivational effects of drugs: Methods which illustrate some general problems in psychopharmacology. Psychopharmacologia, 1960, 1, 169-199.

STEIN, L., \& Berger, B. Psychopharmacology of 7-chloro-5 (chlorophenyl)-1,3-dihydro-3 hydroxy-2H-1, 4-benzodiazepine-2one (orazepam) in squirrel monkey and rat. ArzneimittelForschung, 1971, 7a, 1073-1078.

Vogel, J. R., Beer, B., \& Clody, D. E. A simple and reliable conflict procedure for testing antianxiety agents. Psychopharmacologia, 1971, 21, 1-7.

(Received for publication August 30, 1977; revision accepted November $22,1977$. 